\title{
Selection of Suitable Prodrug Candidates for in vivo Studies via in vitro Studies; The Correlation of Prodrug Stability in Between Cell Culture Homogenates and Human Tissue Homogenates
}

\author{
Yasuhiro Tsume, and Gordon L. Amidon \\ College of Pharmacy, University of Michigan, Ann Arbor, Michigan 48109-1065, USA. \\ Received, June 13, 2012; Revised, July 16, 2012; Accepted, July 17, 2012; Published, July 17, 2012.
}

\begin{abstract}
Purpose. To determine the correlations/discrepancies of drug stabilities between in the homogenates of human culture cells and of human tissues. Methods. Amino acid/dipeptide monoester prodrugs of floxuridine were chosen as the model drugs. The stabilities (half-lives) of floxuridine prodrugs in human tissues (pancreas, liver, and small intestine) homogenates were obtained and compared with ones in cell culture homogenates (AcPC-1, Capan-2, and Caco-2 cells) as well as human liver microsomes. The correlations of prodrug stability in human small bowel tissue homogenate $v s$. Caco-2 cell homogenate, human liver tissue homogenate vs. human liver microsomes, and human pancreatic tissue homogenate vs. pancreatic cell, AsPC-1 and Capan-2, homogenates were examined. Results. The stabilities of floxuridine prodrugs in human small bowel homogenate exhibited the great correlation to ones in Caco-2 cell homogenate (slope $\left.=1.0-1.3, r^{2}=0.79-0.98\right)$. The stability of those prodrugs in human pancreas tissue homogenate also exhibited the good correlations to ones in AsPC-1 and Capan-2 cells homogenates (slope $=0.5-0.8, r^{2}=0.58-0.79$ ). However, the correlations of prodrug stabilities between in human liver tissue homogenates and in human liver microsomes were weaker than others (slope $\left.=1.3-1.9, r^{2}=0.07-0.24\right)$. Conclusions. The correlations of drug stabilities in cultured cell homogenates and in human tissue homogenates were compared. Those results exhibited wide range of correlations between in cell homogenate and in human tissue homogenate $\left(\mathrm{r}^{2}=0.07-0.98\right)$. Those in vitro studies in cell homogenates would be good tools to predict drug stabilities in vivo and to select drug candidates for further developments. In the series of experiments, 5'-O-D-valyl-floxuridine and 5'-O-L-phenylalanyl-Ltyrosyl-floxuridine would be selected as candidates of oral drug targeting delivery for cancer chemotherapy due to their relatively good stabilities compared to other tested prodrugs.
\end{abstract}

This article is open to POST-PUBLICATION REVIEW. Registered readers (see "For Readers") may comment by clicking on ABSTRACT on the issue's contents page.

\section{INTRODUCTION}

It is extremely important to understand the pharmacokinetic characteristics of drug candidates for drug development. Learning the membrane permeabilities and the metabolic stabilities of drug compounds would be important information to select drug candidates. The in vitro studies of membrane permeability and metabolic stability are routinely examined at the early discovery stage in the development of new drugs. Those in vitro experimental systems using the preparations from human should reasonably predict in vivo in human. The in vitro assay systems with intestinal epithelial cells such as Caco-2 cell and HT29 cell for drug membrane permeability and with human liver microsomes and hepatocytes for drug stability/metabolism have been widely utilized due to their convenience and cost effect (1-4). Human intestinal epithelial Caco-2 cell assays for drug permeability have become the standard in the early drug discovery and development $(1,3)$. It is easier and faster with this in vitro system to assess the oral absorption of drugs, to understand the mechanistic basis of drugs, and to characterize intestinal transport mechanism including active and efflux transporters (5, 6). To predict human pharmacokinetics of intestinal availability, human intestinal tissues, human intestinal microsomes and Caco-2 cell homogenate are used to determine the drug stability at the intestinal transit process (7-14).

Corresponding Author: Gordon L. Amidon, College of Pharmacy, The University of Michigan, 428 Church Street, Ann Arbor, MI. Email: glamidon@umich.edu 
The prediction of drug metabolism in human hepatocytes has become more accurate with the available preparations from human. Cryopreserved human hepatocytes and human liver microsomes are widely used to predict in vivo hepatic clearance in human (15-18). Those in vitro experimental systems have been performed enormously as reliable and relatively faster in vitro model systems to evaluate the pharmacokinetics of drug candidates. Cancer is a major health problem in the world and causes one in four deaths in the United States (19). Pancreatic cancer is the fourth highest death in male and female and has a low survival rate (19). The therapy for pancreatic cancer is limited to surgical resection, chemotherapy and radiation therapy because of the difficulties of early diagnosis (20-22). Chemotherapeutic treatment causes cancer patients the adverse effects in non-tumor cells. Therefore, the improvement of therapeutic efficacy has been a major objective. In order to increase tumor selectivity, different approaches have been examined. Prodrug approaches, one of those approaches, have been widely utilized to achieve that goal. Gemcitabine, irinotecan, floxuridine, and capecitabine are prodrug forms of useful chemotherapeutic agents. Floxuridine, 5-fluoro-2'deoxyuridine, is an anticancer agent used clinically in the treatment of cancers. The mechanistic pathways of floxuridine and its active metabolite 5FU for antitumor effect are well described $(23,24)$. Several groups have reported that floxuridine exhibits 10 - to 100 -fold higher potency than 5 -FU $(25,26)$. Therefore, the stabilization of the glycosidic bond in floxuridine would lead to more efficient cancer therapy and has been reportedly succeeded by attaching amino acid/dipeptide to 5'position of floxuridine (13). These prodrugs demonstrated better membrane permeability due to the good affinity to PEPT1 transporters in monolayer cell culture studies and better chemical and enzymatic stabilities in vitro $(13,14,27)$. Moreover, the advantage of amino acid/dipeptide monoester prodrugs of floxuridine over their parent drug to permeate AsPC-1 and Capan-2 cells and to inhibit the growth of pancreatic cancer cells has been demonstrated $(13,28)$.

In the present study, in vitro models provide a well-defined environment for specific studies in contrast to the complex host environment of an in vivo model. Monolayer cell cultures and cell and tissue homogenates as well as microsomes have been popular in vitro models for various studies for years. These experiments furnish a great deal of information on the mechanism of drug permeation, metabolism and action in terms of drug targeting delivery. However, in our knowledge, there has little information regarding the correlation between those in vitro cells and human tissues. In this report, at the stability point of view, the in vitro prodrug stability in human tissue homogenates was examined and compared with one in corresponding human cell homogenates. The correlation of those drug stabilities in human tissue and cell homogenates was compared with the corresponding drug/prodrug stabilities. We selected floxuridine prodrugs as test compounds, which have displayed the better membrane permeability than their parent drug, floxuridine, for this set of experiments $(13,14$, 27, 29-31). The outcome of those results would give a better selection of drug candidates for drug targeting delivery in vivo system.

\section{MATERIALS AND METHODS}

\section{Materials}

Floxuridine was obtained from Lancaster (Windham, NH). The tert-butyloxycarbonyl (Boc) protected amino acids Boc-L-isoleucine, Boc-Lvaline, Boc-D-valine, Boc-L-phenylalanine, BocL-leucine, Boc-L-phenylalanalyl-L-glycine, Boc-Lvalyl-L-phenylalanine, and Boc-L-phenylalanyl-Ltyrosine were obtained from Chem-Impex (Wood Dale, IL). Human liver microsomes S9 were obtained from Celesis (Chicaco, IL). Human tissue samples were provided from the Tissue Procurement Core of the University of Michigan Comprehensive Cancer Center. Acetonitrile, highperformance liquid chromatography (HPLC) grade and liquid chromatography-mass spectrometry (LCMS) grade, was obtained from Fisher Scientific (St. Louis, MO). N,N-dicyclohexylcarbodiimide (DCC), $\mathrm{N}, \mathrm{N}$-dimethylaminopyridine (DMAP), and trifluoroacetic acid (TFA) and all other reagents and solvents were purchased from Aldrich-Aldrich Chemical Co. (Milwaukee, WI). Cell culture reagents were obtained from Invitrogen (Carlsbad, CA) and cell culture supplies were obtained from Corning (Corning, NY) and Falcon (Lincoln Park, NJ). All chemicals were either analytical or HPLC grade.

\section{Synthesis of Floxuridine Prodrugs}

The synthesis and characterization of 5'-mono amino acid and $5^{\prime}$-dipeptide ester prodrugs of 
floxuridine have been reported previously(13, 27, 31 ). Amino acid and dipeptide monoester prodrugs of floxuridine were synthesized in a similar manner. Briefly, Boc-protected amino acids or dipeptides (1.1 mmole), DCC (1.1 mmole), and DMAP (0.1 mmole) were allowed to react with floxuridine (1 mmole) in $7 \mathrm{~mL}$ of dry DMF for $24 \mathrm{hr}$. The reaction progress was monitored by TLC (ethyl acetate) and DMF was removed under vacuum at $40^{\circ} \mathrm{C}$. The residue was extracted with ethyl acetate $(30 \mathrm{~mL})$ and washed with water $(2 \times 20 \mathrm{~mL})$, and saturated $\mathrm{NaCl}(20 \mathrm{~mL})$. The organic layer was dried over $\mathrm{MgSO}_{4}$ and concentrated under vacuum. The reaction yielded a mixture of 3'-amino acid/dipeptide monoester, 5'-amino acid/dipeptide monoester, and 3',5'-amino acid/dipeptide diester floxuridine prodrugs. The three spots observed on TLC were separated (dichloromethane (DCM)/methanol, 20:1) and purified using a preparative HPLC purification system. Fractions from each spot were concentrated under vacuum separately. The Boc group was cleaved by treating the residues with $5 \mathrm{~mL}$ TFA:DCM (1:1). After $4 \mathrm{hr}$, the solvent was removed and the residues were reconstituted with water and lyophilized. The TFA salts of amino acid prodrugs of floxuridine were obtained as white fluffy solids. The combined yield of floxuridine prodrugs was $\sim 60 \%$. HPLC was used to evaluate the prodrug purity. Prodrugs were between $90-99 \%$ pure. These prodrugs were easily separated from parent drug by HPLC. Electrospray ionization mass spectra (ESI-MS) were obtained on a Micromass LCT ESI-MS. The observed molecular weights of all prodrugs were found to be consistent with that required by their structure. The structural identity of the prodrugs was then confirmed using proton nuclear magnetic resonance spectra $\left({ }^{1} \mathrm{H}\right.$ NMR). ${ }^{1} \mathrm{H}$ NMR spectra were obtained on a 300 MHz Bruker DPX-300 NMR spectrometer.

\section{Cell Culture}

Caco-2 cells (passages 30-40) and Capan-2 cells (passages 50-54) from American Type Culture Collection (Rockville, MD) were routinely maintained in DMEM and RPMI-1640 containing $10 \%$ fetal bovine serum at $5 \% \mathrm{CO}_{2}$ and $90 \%$ relative humidity at $37^{\circ} \mathrm{C}$, respectively. All cells were grown in antibiotic-free media.

\section{Analysis of Hydrolysis; Cell homogenates}

The preparation of cell homogenates has been reported previously (13). Confluent Caco-2, Capan-
2, and AsPC-1 cells were rinsed with saline twice. The cells were washed with $5 \mathrm{~mL}$ of $\mathrm{pH} 7.4$ phosphate buffer $(10 \mathrm{mmol} / \mathrm{l})$, lysed by ultrasonication (Micro ultrasonic cell disrupter Model KT40, Kontes, Vineland, NJ), and were pelleted by centrifugation for $5 \mathrm{~min}$ at $1,000 \mathrm{xg}$. Protein amount was quantified with Bio-Rad (Hercules, CA) DC Protein Assay using bovine serum albumin as a standard. The protein amount was adjusted to either $500 \mu \mathrm{g} / \mathrm{mL}$ or $1000 \mu \mathrm{g} / \mathrm{mL}$ and the hydrolysis reactions were carried out in 96well plates (Corning). Caco-2, AsPC-1, and Capan2 cell suspensions $(250 \mu \mathrm{L})$ were placed in triplicate wells, the reactions started with the addition of substrate, and cells were incubated at $37^{\circ} \mathrm{C}$ for $120 \mathrm{~min}$. At the desired time point, sample aliquots $(35 \mu \mathrm{L})$ were removed and added to $150 \mu \mathrm{L}$ of acetonitrile (ACN) containing 0.1\% TFA. The mixtures were filtered with a $0.45 \mu \mathrm{m}$ filter at $1,000 \mathrm{xg}$ for $10 \mathrm{~min}$ at $4^{\circ} \mathrm{C}$. The filtrate was then analyzed via reverse-phase LCMS.

\section{Analysis of Hydrolysis; Human Tissue Homogenates}

The obtained human tissues were rinsed with saline five times. The tissues were washed with $5 \mathrm{~mL}$ of pH 7.4 phosphate buffer $(10 \mathrm{mmol} / \mathrm{l})$ and lysed by homogenizer (Tissue tearor Model 985370, Biospec Product Inc., Bartlesville, OK) and ultrasonication (Micro ultrasonic cell disrupter Model KT40, Kontes, Vineland, NJ), and were pelleted by centrifugation for $5 \mathrm{~min}$ at $1,000 \mathrm{xg}$. Protein amount was quantified with Bio-Rad (Hercules, CA) DC Protein Assay using bovine serum albumin as a standard. The protein amounts were adjusted to 500 $\mu \mathrm{g} / \mathrm{mL}$ and $1000 \mu \mathrm{g} / \mathrm{mL}$ for human pancreas and small intestine, respectively. The hydrolysis reactions were carried out and analyzed as described above.

\section{DATA ANALYSIS}

The initial rates of hydrolysis were used to obtain the apparent first-order rate constants and to calculate the half-lives. The apparent first-order degradation rate constants of various floxuridine prodrugs at $37^{\circ} \mathrm{C}$ were determined by plotting the logarithm of prodrug remaining as a function of time. The slopes of these plots are related to the rate constant, $\mathrm{k}$, and given by

$$
\mathrm{k}=2.303 \times \text { slope }(\log \mathrm{C} \text { vs. time })
$$


The degradation half-lives were then calculated by the equation,

$$
\mathrm{t}_{1 / 2}=0.693 / \mathrm{k}
$$

\section{STATISTICAL ANALYSIS}

Statistical significance was evaluated with GraphPad Prism v. 3.0 by performing one-way analysis of variance with post-hoc Tukey's test to compare means. A $p$ value of $<0.05$ was considered significant.

\section{LC-MS Analysis}

The LC-MS analytical method of 5'-mono amino acid and 5'-dipeptide ester prodrugs of floxuridine has been reported previously (32). The LC-MS analysis of amino acid and dipeptide monoester prodrugs of floxuridine was modified and performed in a similar manner. Briefly, LC-MS analysis of the uptake drug amount was performed in triplicate on LCMS-2010EV (Shimadzu Scientific Instruments, Kyoto, Japan) equipped with an ESI (electrospray ionization) source. The Shimadzu LC-MS system consisting of a Shimadzu LC-20AD pump with DGU-20A in-line vacuum degasser units, and SIL-20HT autosampler with a Xterra MS C-18 column $(5 \mu \mathrm{m}, 50 \times 2.1 \mathrm{~mm})$ was used for the separation and the effluent from the column was directly to the ionization source. The system was controlled by Shimadzu LCMS solution software (version 3 ) to collect and process data. The mobile phase consisted of water containing $0.1 \%$ formic acid (Solvent A) and acetonitrile containing $0.1 \%$ formic acid (Solvent B) for floxuridine prodrugs and water containing $0.1 \%$ ammonium hydroxide (Solvent A) and acetonitrile containing $0.1 \%$ ammonium hydroxide (Solvent B) for floxuridine with the solvent B gradient changing from $2-90 \%$ at a rate of $25 \% / \mathrm{min}$ during a $12 \mathrm{~min}$ run. The ESI probe was operated with a detector voltage of $1.5 \mathrm{kV}$, CDL temperature of $250{ }^{\circ} \mathrm{C}$, heat block of $200{ }^{\circ} \mathrm{C}$, and nebulizing gas flow of 1.2 $\mathrm{mL} / \mathrm{min}$ in negative mode for 5-FdUrd and 5-FU, and in positive mode for floxuridine prodrugs. The drying gas was $\mathrm{N}_{2}$ delivered at $0.1 \mathrm{MPa}$.

\section{Preparative HPLC}

The purification of synthesized test compounds has been reported previously (28). The purification was performed on a Shimadzu preparative HPLC system (Shimadzu Scientific Instruments, Kyoto, Japan). The Shimadzu preparative HPLC system consisted of two Shimadzu pumps (model LC-8A) with Shimadzu system controller (model SCL-10A), a Shimadzu prominence diode array (PDA) detector (model SPD-M20A) with a $10 \mathrm{~mL}$ sample loop controlled by LCsolution software (version 1.23). Samples were resolved in a Waters $\mathrm{XBridge}^{\mathrm{TM}} \mathrm{C}_{18}$ reverse-phase column $(5 \mu \mathrm{m}, 30 \times 250 \mathrm{~mm}$, Milford, MA, USA) for preparative separation. The mobile phase consisted of water containing $0.1 \%$ TFA (Solvent A) and acetonitrile containing 0.1\% TFA (Solvent B) with the solvent B gradient changing from $5-90 \%$ at a rate of $2 \% / \mathrm{min}$ over a 30 min run. The flow rate was $15 \mathrm{~mL} / \mathrm{min}$ and the injection volume was $0.5 \mathrm{~mL}$. The detection wavelengths were $254 \mathrm{~nm}$ and $275 \mathrm{~nm}$.

\section{RESULTS}

\section{Floxuridine Prodrugs}

The synthesis of the prodrugs and their characterization have been described in previous reports $(13,14,27,31)$. The structures of mono amino acid and dipeptide monoester prodrugs of floxuridine and floxuridine were shown in Figure1.

The prodrug degradation was studied in Caco-2, AsPC-1, and Capan-2 cell homogenates, in human liver microsomes, and in human tissue homogenates. These conditions were selected for the targeting delivery of orally administered cancer drugs, at the oral drug absorptive site, at the major metabolic organ in systematic circulation and first pass metabolism, and at the cancer target site. The estimated half-lives $\left(t_{1 / 2}\right)$ were obtained from linear regression of pseudo-first-order plots of prodrug concentration $v s$. time for floxuridine prodrugs and floxuridine in all experiments. Prodrug metaobolites such as floxuridine and 5-FU were monitored along with the disappearance in those experiments. However, mass balance was not achieved because 5-FU was metabolized further and those metabolites beyond 5-FU were not quantified. 


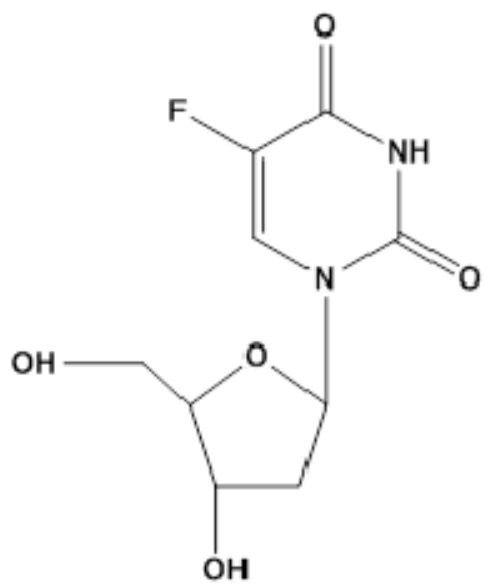

Floxuridine

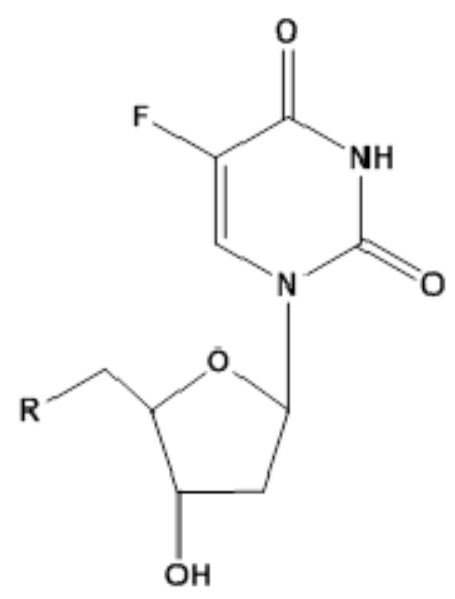

5 '- monoester prodrugs of floxuridine

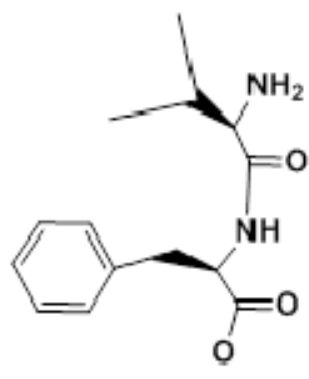

$\mathrm{L}=$ Valyl=L-Phenylalanine

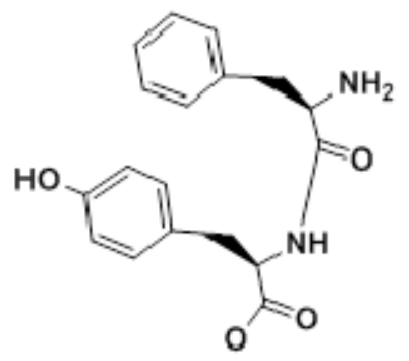

L-Phenylalanyl-L-Tyrosine

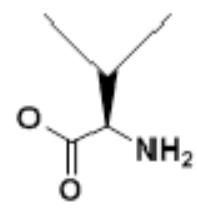

L-Valine

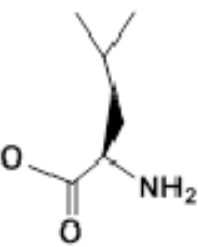

L-Leucine<smiles>CC(C)[C@H](N)C(=O)O</smiles>

D-Valine

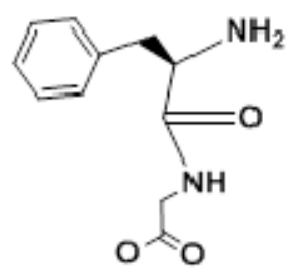

L-Phenylalanyl-L-Glycine

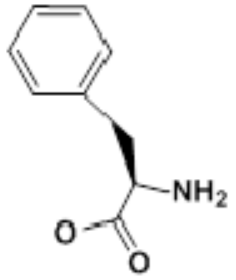

L-Phenylalanine

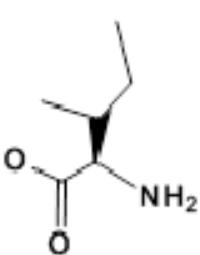

L-Isoleucine

Figure 1. Structures of mono amino acid and dipeptide ester prodrugs of floxuridine

\section{Stability of Floxuridine Prodrugs in Caco-2 cell} and Human Small Intestinal Tissue Homogenates

The experiments concerning prodrug stability for oral administered drugs were performed in Caco-2 cell and human small intestinal tissue homogenates in $\mathrm{pH} 7.4$ phosphate buffer at $37^{\circ} \mathrm{C}$. The half-lives of floxuridine prodrugs and their parent drug, floxuridine, in $\mathrm{pH} 7.4$ buffer alone, in Caco-2 cell homogenate, and in human small intestinal tissue homogenate are listed in Table 1. Floxuridine-3'proline was stable in phosphate buffer, in Caco-2 cell homogenate, and in human small bowel tissue homogenate. 5'-O-D-valyl-floxuridine and 5'-O-Lphenylalanyl-L-tyrosyl-floxuridine were the most stable amino acid and dipeptide monoester prodrugs of floxuridine, respectively, in Caco-2 cell and human small bowel tissue homogenates. 5'-O-Dvalyl-floxuridine was 16.1 - to 11.3 -fold more stable in Caco-2 and human intestinal tissue homogenates than 5'-O-L-valyl-floxuridine, respectively. The stability of 5'-O-L-isoleucyl-floxuridine in human small bowel tissue homogenate was reduced 13.1fold, the biggest reduction among test compounds, when it was compared to one in Caco-2 cell 
homogenate, suggesting there might be specific metabolizing enzymes in human small intestine for 5'-O-L-isoleucyl-floxuridine. All prodrugs exhibited 1.6- to 45.6-fold shorter half-lives in cell/tissue homogenates than in $\mathrm{pH} 7.4$ phosphate buffer suggesting enzyme-catalyzed hydrolysis. The half-lives of floxuridine prodrugs and floxuridine in Caco-2 cell homogenate exhibited a good linear correlation (slope $=1.3, r^{2}=0.73, p<0.05$ ) with the half-lives of those compounds in human small intestinal tissue homogenate (Figure2). The linear correlation of drug stabilities in those homogenates is improved without the data of 5'-O-L-isoleucylfloxuridine (slope $=1.0, r^{2}=0.98, p<0.05$ ). This result suggests that the drug stability in Caco- 2 cell homogenate would predict the in vivo drug stability in human small intestine. 5'-O-D-valyl-floxuridine, 5'-O-L-phenylalanyl-L-tyrosyl-floxuridine, and 5'O-L-valyl-L-phenylalanyl-floxuridine would be good candidates for improving oral bioavailability due to their enhanced stabilities at human small intestine.

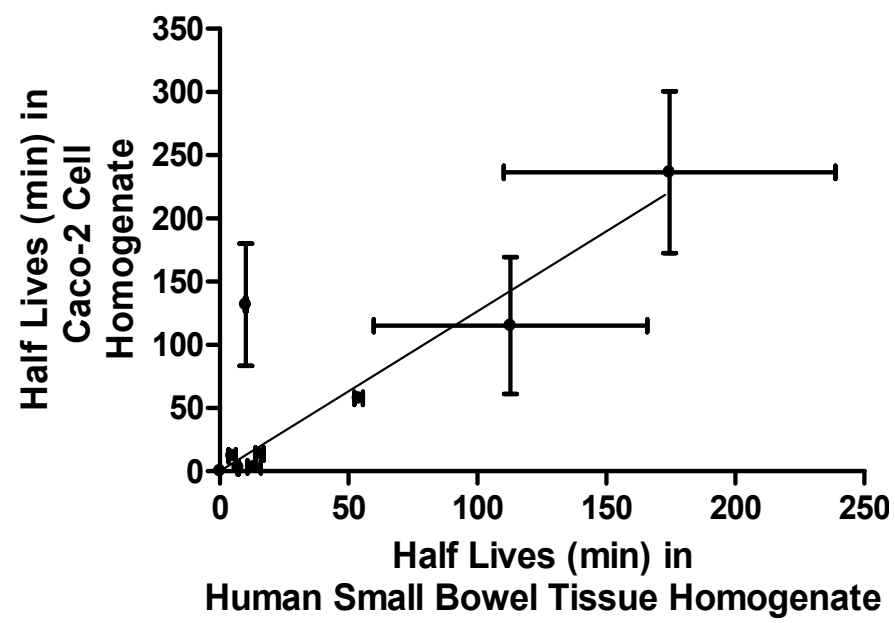

Figure 2. The correlation of prodrug stability (half life; $\mathrm{t}_{1 / 2}$ ) between in human small bowel homogenate (nontumor) and in Caco-2 cell homogenate (slope $=1.3, r^{2}=$ $0.73, p<0.05)$. The estimated drug half-lives were calculated based on disappearance of original prodrug forms. Data are expressed as mean \pm S.D., $\mathrm{n}=3-6$.

\section{Stability of Floxuridine Prodrugs in Human Liver Microsomes and Human Liver Tissue Homogenates}

Due to the limited tumor tissue supply, four floxuridine prodrugs, 5'-O-D-valyl-floxuridine, 5'O-L-isoleucyl-floxuridine, 5'-O-L-valyl-L- phenylalanyl-floxuridine, and 5'-O-L-phenylalanylL-tyrosyl-floxuridine, were selected to determine their stabilities in human tumor liver tissue homogenate based on their enzymatic stabilities in human liver microsomes and human non-tumor liver tissue homogenate. For the comparison purpose, 5'-O-L-valyl-floxuridine and floxuridine$3^{\prime}$-proline were selected as the optic isomer of 5'-OD-valyl-floxuridine and a stable marker prodrug, respectively. The half-lives of tested drugs in human liver microsomes and in human liver tissue homogenates are listed in Table 2. Floxuridine-3'proline exhibited no significant degradation in both human liver microsomes and human liver tissue homogenate over $2 \mathrm{hr}$. 5'-O-D-valyl-floxuridine and 5'-O-L-phenylalanyl-L-tyrosyl-floxuridine were the most stable amino acid and dipeptide monoester prodrugs of floxuridine, respectively, in human liver microsomes and in human liver tissue homogenate. 5'-O-D-valyl-floxuridine in human liver microsomes was at least 37 -fold more stable than in human liver tissue homogenates, while 5'-OL-phenylalanyl-L-tyrosyl-floxuridine showed the same stability in all tested conditions (Table 2). 5'O-D-valyl-floxuridine exhibited 243-fold better stability in human liver microsomes and 3- to 10fold better stability in human liver tissue homogenates than 5'-O-L-valyl-floxuridine, the optical isomer of 5'-O-D-valyl-floxuridine. 5'-O-Lisoleucyl-floxuridine and 5'-O-L-valyl-Lphenylalanyl-floxuridine exhibited 3.7- to 123- fold shorter half-lives in human liver tissue homogenates than ones in human liver microsomes. The halflives of $5^{\prime}$-O-L-phenylalanyl-L-glycyl-floxuridine and 5'-O-L-leucyl-floxuridine in human liver microsomes were reduced 5-fold and 4-fold in human non-tumor liver tissue homogenate. The linear correlations of half-lives of all prodrugs tested in human liver microsomes and human liver tissue homogenates were poor (human liver microsomes vs. human tumor liver tissue homogenate; slope $=1.9 r^{2}=0.24, p=0.13$, human liver microsomes $v s$. human non-tumor liver tissue homogenate; slope $=1.3 r^{2}=0.07, p=0.27$ ) (Figure3a and Figure3b). However, the linear correlation of half-lives of all prodrugs tested between human liver tissue homogenates was significant (human non-tumor liver tissue homogenate $v s$. human tumor liver tissue homogenate; slope $=0.6 r^{2}=0.91, p<0.01$ ) (Figure3c). 
Table 1. Stability of prodrugs in Caco-2 cell homogenate and human small intestinal tissue homogenate.

\section{Half-lives (min)}

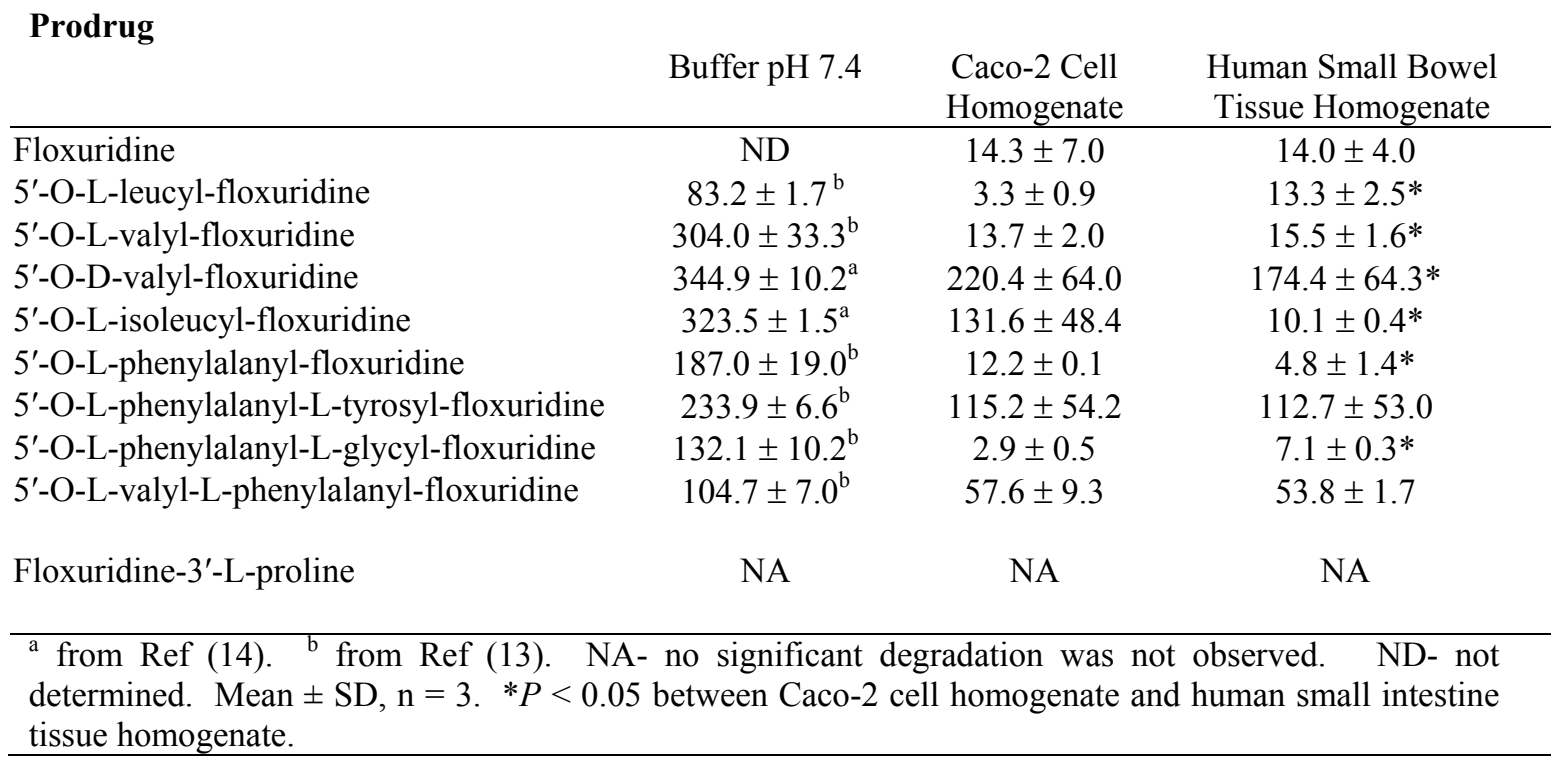

This result suggests that 1 ) the estimated stabilities of those prodrugs in human liver microsomes might be overestimated due to the reduction of half-lives for those tested prodrugs in human tissue homogenates and 2) the enzymes in human tumor liver homogenate degrades tested prodrugs quicker than ones in the homogenate of human non-tumor liver. Floxuridine exhibited less than $0.2 \mathrm{~min}$ and $5.0 \mathrm{~min}$ half-lives in human liver microsomes and in human non-tumor liver tissue homogenate, respectively.

\section{Stability of Floxuridine Prodrugs in AsPC-1 Cell and Capan-2 cell homogenates and in Human Pancreas Tissue Homogenate}

The half-lives of floxuridine prodrugs and floxuridine in pancreatic cancer cell, AsPC-1 and Capan-2 cells, homogenates and in human pancreas (non-tumor) tissue homogenate are listed in Table 3. The half-life of 5'-O-L-isoleucyl-floxuridine in human pancreas tissue homogenate was only significantly shorter than ones in AsPC-1 and Capan-2 cell homogenates. The half-lives of 5'-OL-valyl-L-phenylalanyl-floxuridine were similar throughout three different conditions, AsPC-1 cell, Capan-2 cell, and human pancreas tissue homogenates. Surprisingly, floxuridine exhibited good stability in human pancreas tissue homogenate.
With exception of 5'-O-L-isoleucyl-floxuridine and 5'-O-L-valyl-L-phenylalanyl-floxuridine, all tested prodrugs of floxuridine and floxuridine exhibited longer half-lives in human pancreas tissue homogenate than ones in pancreatic cancer cell homogenates. Floxuridine prodrugs, which are stable in human non-tumor pancreas tissue homogenate and exhibit shorter half-life in cancer cell homogenates, would be ideal candidates for the targeting delivery of pancreatic cancer chemotherapy and the improvement of therapeutic efficacy. The half-lives of floxuridine prodrugs and floxuridine in human non-tumor pancreas tissue homogenate exhibited good liner correlations with ones in the AsPC-1 cell homogenate (slope $=0.8, r^{2}$ $=0.58, p<0.05)$ and Capan-2 cell homogenate (slope $=0.5, r^{2}=0.79, p<0.05$ ), respectively (Figure4). This correlation of half-lives between in human non-tumorous pancreas tissue homogenate and in those pancreatic cancer cell homogenates are stronger when the points of 5'-O-L-phenylalanyl-Lglycyl-floxuridine are removed (AsPC-1; slope $=$ $0.9, r^{2}=0.69, p<0.05$, Capan-2; slope $=0.5, r^{2}=$ $0.91, p<0.05)$. Those results suggest that the stability result in AsPC-1 cell homogenate would estimate the drug stability in human pancreas very well and may be more revealing in vivo stability of drugs than the one in Capan-2 cell homogenate. 

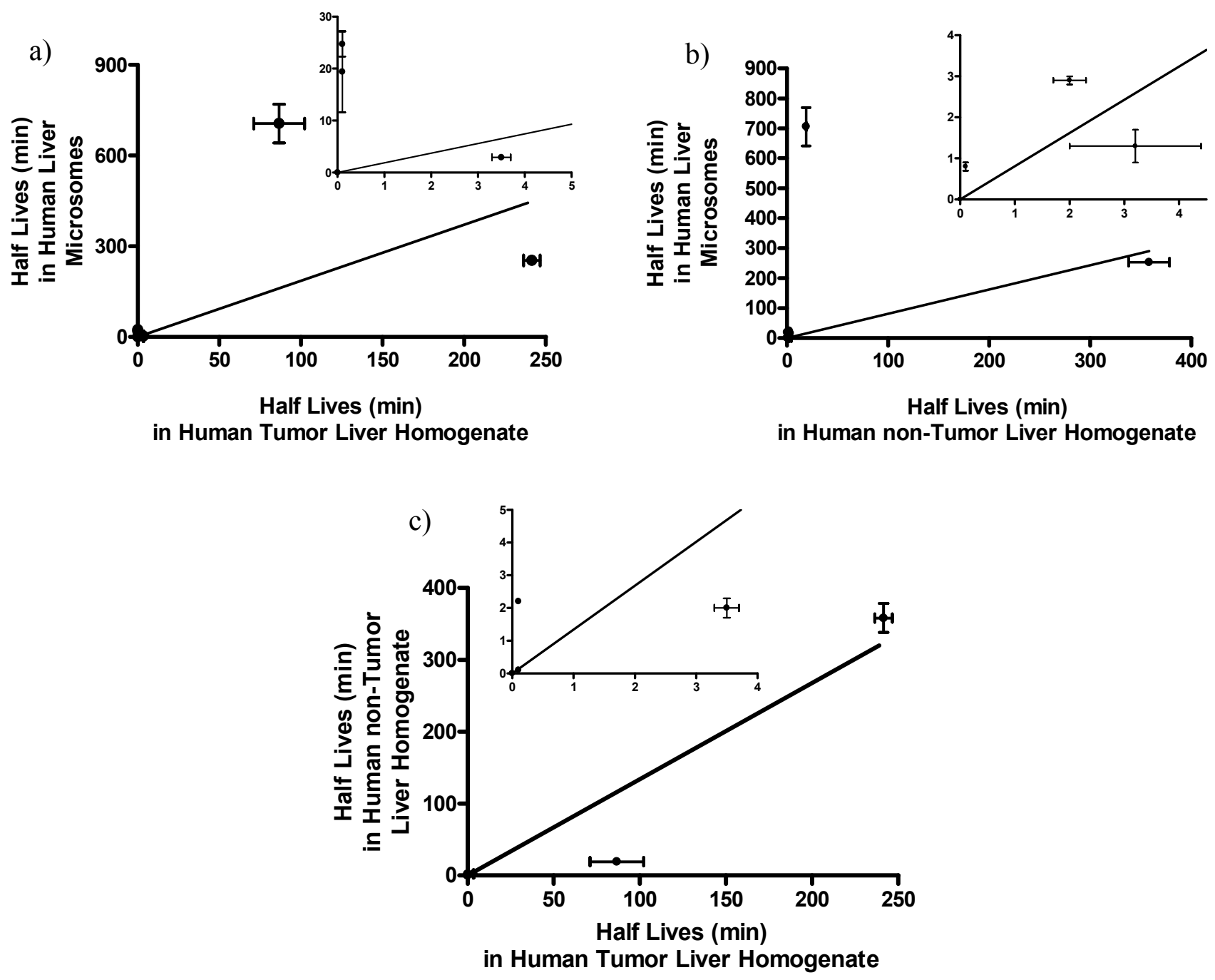

Figure 3. The correlations of prodrug stability (half life) a) between in human liver microsomes and in human tumor liver tissue homogenate (slope $\left.=1.9, r^{2}=0.24, p=0.13\right)$, b) between in human liver microsomes and in human non-tumor liver tissue homogenate (slope $=1.3, r^{2}=0.07, p=0.27$ ), and c) between in human non-tumor liver tissue homogenate and in human tumor liver tissue homogenate (slope $=0.6, r^{2}=0.91, p<0.05$ ). The estimated drug half-lives were calculated based on disappearance of original prodrug forms. Data are expressed as mean \pm S.D., $\mathrm{n}=3-6$. Inset figures the data for short half-lives rescaled for clarity.

\section{DISCUSSION}

In vitro models provide a well defined environment for specific studies in contrast to the complex host environment of an in vivo model. Monolayer cell culture has been popular in in vitro models to evaluate the membrane permeability test agents for years. These experiments furnish a great deal of information on the mechanism of drug action and improvements in terms of drug targeting delivery. Also, in vitro models for evaluating drug stability/bioconversion are potentially of great value at the early stage of drug discovery and development. Those in vitro experimental systems have been performed enormously as reliable model systems to evaluate the pharmacokinetics of drug candidates. The fraction absorbed, intestinal availability and hepatic availability are the most important factors to predict oral bioavailability and pharmacokinetics. For the assessment of drug absorption, Caco-2 cell monolayer is a convenient tool to predict the membrane permeability of drug candidates and have been widely used to identify potential absorption problems of those (33-35). To predict human pharmacokinetics of intestinal availability, human intestinal tissues, human 
intestinal microsomes and Caco- 2 cell homogenate are used to determine the drug stability at the intestinal transit process (7-14). The prediction of drug metabolism in human hepatocytes has become more accurate with the available preparations from human. Cryopreserved human hepatocytes and human liver microsomes are widely used to predict in vivo hepatic clearance in human (15-18).

The prodrug strategies have been investigated for anti-viral and anti-cancer agents to improve drug absorption and efficacy of drug delivery to target sites. Antiviral drugs, valacyclovir and valgenciclovir, are commercially successful examples of amino acid ester prodrug approaches by improving oral absorption of poorly permeable drugs and by efficiently bioconverting prodrugs by the specific activation enzyme, valacyclovirase (3640). It has been reported that the carrier-mediatedtransporters such as oligopeptide transporters in the GI tract have attributed the improvement of oral bioavailability of those antiviral prodrugs $(41,42)$. Oligopeptide transporters are the most attractive target in prodrug strategies because of their broad substrate specificities and distribution throughout the small intestine. A variety of promoieties have been examined as suitable substrates for this carrier-mediated-transporter (43-47). Previously, we have demonstrated amino acid and dipeptide monoester prodrugs for their suitability as substrates for the PEPT1 transporter and for their improved membrane permeability $(13,14,30,31$, $48,49)$. Those prodrugs also enhanced the stability against metabolic enzymes such as thymidine phosphorylase (TP), cytidine deaminase (CDA), and dihydropyrimidine dehydrogenase (DPD) in vitro settings $(13,30,48,49)$.

In the present study, amino acid and dipeptide monoester prodrugs of floxuridine were selected as model prodrugs. The stability studies of amino acid/dipeptide monoester prodrugs of floxuridine with a simple in vitro system in various cell and human tissue homogenates have been carried out to select better candidate prodrugs for oral drug targeted delivery in in vivo studies. The rates of disappearance for those prodrugs as well as their parent drug, floxuridine, in cell homogenates and microsomes were compared with ones in human tissue homogenates. This comparison might corroborate that the stability tests of those compounds in culture cell homogenates reflect the fate of those compounds in human tissues and in vivo. In vitro models for evaluating prodrug stability are potentially of great value at the early stage of drug discovery and the stability results of floxuridine prodrugs in cell homogenates showed some correlations $\left(r^{2}=0.07-0.79\right)$ with ones in human tissue homogenates.

Prodrugs with unnatural form of amino acid, Dform, have been investigated and exhibited their improved enzymatic stabilities $(14,50,51)$. 5'-OD-valyl-floxuridine was the most stable prodrug among tested prodrugs and exhibited 3- to 243-fold higher enzymatic stability than 5'-O-L-valylfloxuridine in all tested conditions. 5'-O-Lisoleucyl-floxuridine was the second most stable prodrug in all three cell homogenates, Caco-2 cell, AsPC-1 cell and Capan-2 cell, but exhibited 3- to 19-fold faster metabolism in human small bowel, non-tumor liver and pancreas tissue homogenates. 5'-O-L-phenylalanyl-L-tyrosyl-floxuridine exhibited relatively longer half-lives in all conditions except ones in pancreatic cancer cell homogenates which displaying quicker metabolism $\left(\mathrm{t}_{1 / 2} ; 59.7 \mathrm{~min}\right.$ in AsPC-1 cell and $42.8 \mathrm{~min}$ in Capan-2 cell). All tested prodrugs exhibited longer half-lives in human pancreas tissue homogenate than in AsPC-1 cell and Capan-2 cell homogenates except 5'-O-L-isoleucyl-floxuridine and 5'-O-Lvalyl-L-phenylalanyl-floxuridine. This result suggests the overexpression of metabolic enzymes, which associate with rapid degradation/metabolism of drug compounds, in cancer cells (52-54). With the exception of 5'-O-L-isoleucyl-floxuridine, the stability of floxuridine prodrugs in Caco-2 cell homogenate was similar to one in human small intestine tissue homogenate. Those stability data exhibited the good liner correlation (slope $=1.0$ $\left.1.3, r^{2}=0.73-0.98, p<0.05\right)$, suggesting that the stability in Caco-2 homogenate would predict the intestinal availability of test compounds well (Figure 2). The stability results of floxuridine prodrugs in human liver microsomes tended to underestimate their stabilities in human liver tissue homogenate (Table 2 and Figure 3a-c). This might be that liver microsomes mainly provide the tool to study cytochrome P-450 (CYP)-mediated metabolism, while liver tissue homogenates encompass full complement of enzymes and cofactors $(55,56)$. Conversely, the stability results of floxuridine prodrugs in Capan-2 and AsPC-1 cell homogenates tended to underestimate their stability in human pancreatic tissue homogenate (Table 3 and Figure 4). 
Table 2: Stability of floxuridine prodrugs in human liver microsomes and human liver tissue homogenate.

\begin{tabular}{|c|c|c|c|}
\hline \multirow[b]{2}{*}{ Prodrug } & \multicolumn{3}{|c|}{ Half-lives (min) } \\
\hline & $\begin{array}{l}\text { Human Liver } \\
\text { Microsomes }\end{array}$ & $\begin{array}{c}\text { Human non-Tumor } \\
\text { Liver Tissue } \\
\text { Homogenate }\end{array}$ & $\begin{array}{l}\text { Human Tumor } \\
\text { Liver Tissue } \\
\text { Homogenate }\end{array}$ \\
\hline Floxuridine & $<0.2 \mathrm{~min}$ & $5.0 \pm 2.4$ & ND \\
\hline 5'-O-L-leucyl-floxuridine & $0.8 \pm 0.1$ & $<0.2 \mathrm{~min}$ & ND \\
\hline 5'-O-L-valyl-floxuridine & $2.9 \pm 0.1$ & $2.0 \pm 0.3^{*}$ & $3.5 \pm 0.2 *^{\infty}$ \\
\hline 5'-O-D-valyl-floxuridine & $705.9 \pm 64.2$ & $19.0 \pm 0.2 *$ & $9.4 \pm 0.5^{* \infty}$ \\
\hline 5'-O-L-isoleucyl-floxuridine & $19.4 \pm 7.8$ & $5.2 \pm 0.1$ & $<0.2 \min ^{\infty}$ \\
\hline 5'-O-L-phenylalanyl-floxuridine & $1.3 \pm 0.4$ & $3.2 \pm 1.2$ & ND \\
\hline 5'-O-L-phenylalanyl-L-tyrosyl-floxuridine & $253.0 \pm 36.2$ & $358.3 \pm 20.3$ & $241.4 \pm 5.1$ \\
\hline 5'-O-L-phenylalanyl-L-glycyl-floxuridine & $15.9 \pm 1.9$ & $3.2 \pm 0.3^{*}$ & ND \\
\hline 5'-O-L-valyl-L-phenylalanyl-floxuridine & $24.7 \pm 2.4$ & $2.2 \pm 0.0^{*}$ & $<0.2 \min ^{* \infty}$ \\
\hline Floxuridine-3'-L-proline & NA & NA & NA \\
\hline
\end{tabular}

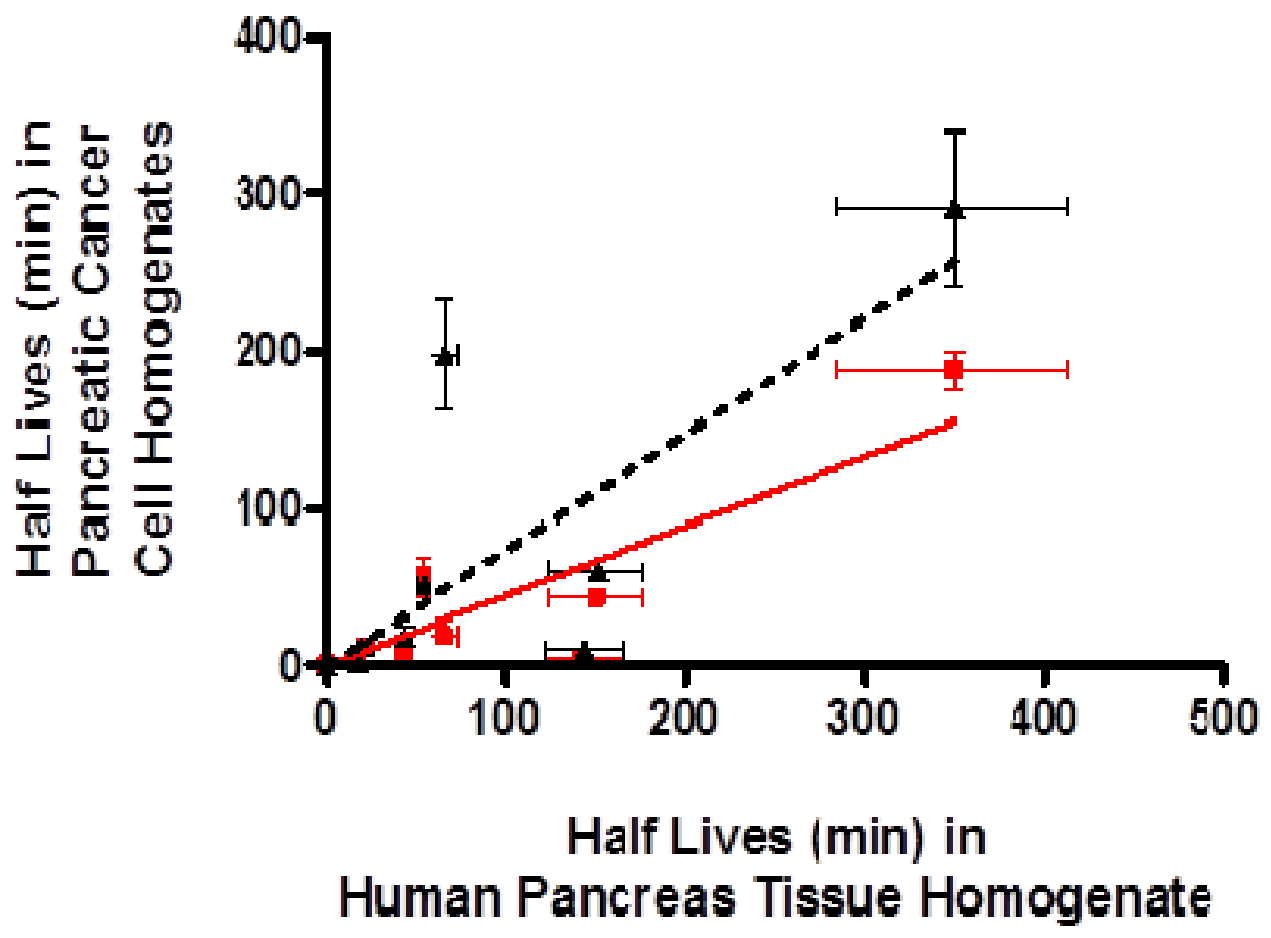

Figure 4. The correlation of prodrug stability (half life; $\mathrm{t}_{1 / 2}$ ) between human pancreas tissue homogenate (non-tumor) and pancreatic cancer cell homogenates, AsPC-1 and Capan-2 cell. Triangles $(\boldsymbol{\Delta})$ and a solid line represent the correlation (slope $=0.5, r^{2}=0.58, p<0.05$ ) of prodrug stability between Capan-2 cell and human pancreatic tissue homogenates. Rectangles $(\square)$ and a dotted line represent the correlation (slope $=0.8, r^{2}=0.79, p<0.05$ ) of prodrug stability between AsPC-1 cell and human pancreatic tissue homogenates. The estimated drug half-lives were calculated based on disappearance of original prodrug forms. Data are expressed as mean \pm S.D., $\mathrm{n}=3-6$. 


\begin{tabular}{|c|c|c|c|}
\hline \multirow[b]{2}{*}{ Prodrug } & \multicolumn{3}{|c|}{ Half-lives (min) } \\
\hline & $\begin{array}{l}\text { AsPC-1 Cell } \\
\text { Homogenate }\end{array}$ & $\begin{array}{l}\text { Capan-2 Cell } \\
\text { Homogenate }\end{array}$ & $\begin{array}{c}\text { Human Pancreas } \\
\text { Tissue Homogenate }\end{array}$ \\
\hline Floxuridine & $6.4 \pm 3.2$ & $17.8 \pm 5.8$ & $208.7 \pm 19.4^{* \#}$ \\
\hline 5'-O-L-leucyl-floxuridine & $2.0 \pm 0.1^{\mathrm{a}}$ & $4.7 \pm 2.1^{\mathrm{b}}$ & $16.8 \pm 0.1 * \#$ \\
\hline 5'-O-L-valyl-floxuridine & $18.7 \pm 6.7^{\mathrm{b}}$ & $5.2 \pm 2.4^{\mathrm{b}}$ & $42.7 \pm 0.3^{* \#}$ \\
\hline 5'-O-D-valyl-floxuridine & $290.9 \pm 48.9^{\mathrm{a}}$ & $188.3 \pm 12.1$ & $348.7 \pm 64.2{ }^{* \#}$ \\
\hline 5'-O-L-isoleucyl-floxuridine & $198.0 \pm 70.2^{\mathrm{b}}$ & $139.9 \pm 15.3^{\mathrm{b}}$ & $65.9 \pm 7.2 *^{\#}$ \\
\hline 5'-O-L-phenylalanyl-floxuridine & $11.8 \pm 1.7^{\mathrm{b}}$ & $3.0 \pm 0.1^{\mathrm{b}}$ & $21.9 \pm 2.8^{* \#}$ \\
\hline 5'-O-L-phenylalanyl-L-tyrosyl-floxuridine & $59.7 \pm 1.4^{\mathrm{b}}$ & $42.8 \pm 0.0^{\mathrm{b}}$ & $150.1 \pm 26.9 *^{\#}$ \\
\hline 5'-O-L-phenylalanyl-L-glycyl-floxuridine & $10.2 \pm 0.3^{\mathrm{b}}$ & $4.3 \pm 0.9^{b}$ & $142.7 \pm 21.5^{* \#}$ \\
\hline 5'-O-L-valyl-L-phenylalanyl-floxuridine & $51.6 \pm 4.2^{\mathrm{b}}$ & $56.2 \pm 12.8^{\mathrm{b}}$ & $53.7 \pm 4.8^{*}$ \\
\hline Floxuridine-3'-L-proline & NA & NA & NA \\
\hline
\end{tabular}

This might be that the homogenates of pancreatic cancer cells were used instead of the homogenates of pancreatic non-tumor cells and the expression and activity levels of metabolic enzymes might be different between tumor cells and non-tumor cells $(57,58)$. However, those in vitro stability data in cell homogenates and in liver microsomes offered approximate the stability of test compounds in corresponding human tissue homogenates. With gaining more knowledge in difference between human tissues and cultured cells such as enzyme population, more accurate prediction of drug stability for in vivo would be obtained from in vitro experiments by using the correction factor or the specifically adjusted experimental condition with the homogenates of each cell line on in vitro study.

In conclusion, those in vitro experimental models do not resemble the complexity of in vivo. Those simplified in vitro experiments allow the analysis of single parameters. Those in vitro stability studies of test drugs are neither reflecting in vivo drug stability nor drug stability in specific human tissues in vivo and, moreover, isolated tissue slices can predict in vivo metabolism of test compounds more accurately; however, those in vitro studies would be excellent predictive tools for saving the labor, time, and cost and for screening drug candidates to further developments. Indeed, in those series of in vitro studies, 5'-O-D-valyl- floxuridine and 5'-O-L-phenylalanyl-L-tyrosylfloxuridine could be easily selected as candidates of oral drug targeting delivery for cancer chemotherapy in in vivo studies due to their relatively good stabilities and rapid bioconversion in cancer cell homogenates compared to other tested prodrugs.

\section{ACKNOWLEDGEMENTS}

This work was supported by grants NIGMD2R01GM37188 and was also supported part by the Tissue Procurement Core of the University of Michigan Comprehensive Cancer Center, Grant\#CA46952.

\section{REFERENCES}

1. Artursson P, Palm K, Luthman K. Caco-2 monolayers in experimental and theoretical predictions of drug transport. Adv Drug Deliv Rev. 2001;46(1-3):27-43.

2. Ekins S, Ring BJ, Grace J, McRobie-Belle DJ, Wrighton SA. Present and future in vitro approaches for drug metabolism. J Pharmacol Toxicol Methods. 2000;44(1):313-24.

3. Hidalgo IJ, Raub TJ, Borchardt RT. Characterization of the human colon carcinoma cell line (Caco-2) as a model system for intestinal epithelial permeability. Gastroenterology. 1989;96(3):736-49. 
4. Li AP. Screening for human ADME/Tox drug properties in drug discovery. Drug Discov Today. 2001;6(7):357-66.

5. Matsumoto $\mathrm{S}$, Saito $\mathrm{H}$, Inui $\mathrm{K}$. Transcellular transport of oral cephalosporins in human intestinal epithelial cells, Caco-2: interaction with dipeptide transport systems in apical and basolateral membranes. J Pharmacol Exp Ther. 1994;270(2):498-504.

6. Phung-Ba V, Warnery A, Scherman D, Wils P. Interaction of pristinamycin IA with P-glycoprotein in human intestinal epithelial cells. Eur J Pharmacol. 1995;288(2):187-92.

7. Gupta D, Gupta SV, Lee KD, Amidon GL. Chemical and enzymatic stability of amino acid prodrugs containing methoxy, ethoxy and propylene glycol linkers. Mol Pharm. 2009;6(5):1604-11.

8. Katragadda S, Jain R, Kwatra D, Hariharan S, Mitra AK. Pharmacokinetics of amino acid ester prodrugs of acyclovir after oral administration: interaction with the transporters on Caco-2 cells. Int J Pharm. 2008;362(1-2):93-101.

9. Najlah M, Freeman S, Attwood D, D'Emanuele A. In vitro evaluation of dendrimer prodrugs for oral drug delivery. Int J Pharm. 2007;336(1):183-90.

10. Akabane T, Tabata K, Kadono K, Sakuda S, Terashita S, Teramura T. A comparison of pharmacokinetics between humans and monkeys. Drug Metab Dispos. 2010;38(2):308-16.

11. Vickers AE, Zollinger M, Dannecker R, Tynes R, Heitz F, Fischer V. In vitro metabolism of tegaserod in human liver and intestine: assessment of drug interactions. Drug Metab Dispos. 2001;29(10):126976.

12. Chiba M, Hensleigh M, Lin JH. Hepatic and intestinal metabolism of indinavir, an HIV protease inhibitor, in rat and human microsomes. Major role of CYP3A. Biochem Pharmacol. 1997;53(8):118795.

13. Tsume Y, Hilfinger JM, Amidon GL. Enhanced cancer cell growth inhibition by dipeptide prodrugs of floxuridine: increased transporter affinity and metabolic stability. Mol Pharm. 2008;5(5):717-27.

14. Tsume Y, Vig BS, Sun J, Landowski CP, Hilfinger JM, Ramachandran C, et al. Enhanced absorption and growth inhibition with amino acid monoester prodrugs of floxuridine by targeting hPEPT1 transporters. Molecules. 2008;13(7):1441-54.

15. Blanchard N, Hewitt NJ, Silber P, Jones H, Coassolo $\mathrm{P}$, Lave T. Prediction of hepatic clearance using cryopreserved human hepatocytes: a comparison of serum and serum-free incubations. J Pharm Pharmacol. 2006;58(5):633-41.

16. Chiba M, Ishii Y, Sugiyama Y. Prediction of hepatic clearance in human from in vitro data for successful drug development. Aaps J. 2009;11(2):262-76.
17. Shibata Y, Takahashi H, Chiba M, Ishii Y. Prediction of hepatic clearance and availability by cryopreserved human hepatocytes: an application of serum incubation method. Drug Metab Dispos. 2002;30(8):892-6.

18. Ubeaud G, Schmitt C, Jaeck D, Lave T, Coassolo P. Bosentan, a new endothelin receptor antagonist: prediction of the systemic plasma clearance in man from combined in vivo and in vitro data. Xenobiotica. 1995;25(12):1381-90.

19. Jemal A, Siegel R, Ward E, Hao Y, Xu J, Thun MJ. Cancer statistics, 2009. CA Cancer J Clin. 2009;59(4):225-49.

20. Bramhall SR, Allum WH, Jones AG, Allwood A, Cummins C, Neoptolemos JP. Treatment and survival in 13,560 patients with pancreatic cancer, and incidence of the disease, in the West Midlands: an epidemiological study. $\mathrm{Br}$ J Surg. 1995;82(1):111-5.

21. Bramhall SR, Neoptolemos JP. Advances in diagnosis and treatment of pancreatic cancer. Gastroenterologist. 1995;3(4):301-10.

22. Jemal A, Siegel R, Ward E, Murray T, Xu J, Smigal C, et al. Cancer statistics, 2006. CA Cancer J Clin. 2006;56(2):106-30.

23. Grem JL. 5-Fluorouracil: forty-plus and still ticking. A review of its preclinical and clinical development. Invest New Drugs. 2000;18(4):299-313.

24. Grem JL, Harold N, Shapiro J, Bi DQ, Quinn MG, Zentko S, et al. Phase I and pharmacokinetic trial of weekly oral fluorouracil given with eniluracil and low-dose leucovorin to patients with solid tumors. J Clin Oncol. 2000;18(23):3952-63.

25. Laskin JD, Evans RM, Slocum HK, Burke D, Hakala MT. Basis for natural variation in sensitivity to 5-fluorouracil in mouse and human cells in culture. Cancer Res. 1979;39(2 Pt 1):383-90.

26. Yamada M, Nakagawa H, Fukushima M, Shimizu K, Hayakawa $\mathrm{T}$, Ikenaka $\mathrm{K}$. In vitro study on intrathecal use of 5-fluoro-2'-deoxyuridine (FdUrd) for meningeal dissemination of malignant brain tumors. J Neurooncol. 1998;37(2):115-21.

27. Landowski CP, Vig BS, Song X, Amidon GL. Targeted delivery to PEPT1-overexpressing cells: acidic, basic, and secondary floxuridine amino acid ester prodrugs. Mol Cancer Ther. 2005;4(4):659-67.

28. Tsume Y, Hilfinger JM, Amidon GL. Potential of amino acid/dipeptide monoester prodrugs of floxuridine in facilitating enhanced delivery of active drug to interior sites of tumors: a two-tier monolayer in vitro study. Pharm Res. 2011;28(10):2575-88. doi: 10.1007/s11095-0110485-7.

29. Mittal S, Song X, Vig BS, Amidon GL. Proline prodrug of melphalan targeted to prolidase, a prodrug activating enzyme overexpressed in melanoma. Pharm Res. 2007;24(7):1290-8. 
30. Song X, Lorenzi PL, Landowski CP, Vig BS, Hilfinger JM, Amidon GL. Amino acid ester prodrugs of the anticancer agent gemcitabine: synthesis, bioconversion, metabolic bioevasion, and hPEPT1-mediated transport. Mol Pharm. 2005;2(2):157-67.

31. Vig BS, Lorenzi PJ, Mittal S, Landowski CP, Shin $\mathrm{HC}$, Mosberg HI, et al. Amino acid ester prodrugs of floxuridine: synthesis and effects of structure, stereochemistry, and site of esterification on the rate of hydrolysis. Pharm Res. 2003;20(9):1381-8.

32. Tsume Y, Provoda CJ, Amidon GL. The achievement of mass balance by simultaneous quantification of floxuridine prodrug, floxuridine, 5fluorouracil, 5-dihydrouracil, alpha-fluoro-betaureidopropionate, alpha-fluoro-beta-alanine using LC-MS. Journal of chromatography B, Analytical technologies in the biomedical and life sciences. 2011;879(13-14):915-20.

doi: 10.1016/j.jchromb.2011.02.045.

33. Foger F, Kopf A, Loretz B, Albrecht K, BernkopSchnurch A. Correlation of in vitro and in vivo models for the oral absorption of peptide drugs. Amino Acids. 2008;35(1):233-41.

34. Walter E, Janich S, Roessler BJ, Hilfinger JM, Amidon GL. HT29-MTX/Caco-2 cocultures as an in vitro model for the intestinal epithelium: in vitro-in vivo correlation with permeability data from rats and humans. J Pharm Sci. 1996;85(10):1070-6.

35. Yee S. In vitro permeability across Caco-2 cells (colonic) can predict in vivo (small intestinal) absorption in man--fact or myth. Pharm Res. 1997;14(6):763-6.

36. Jung D, Dorr A. Single-dose pharmacokinetics of valganciclovir in HIV- and CMV-seropositive subjects. J Clin Pharmacol. 1999;39(8):800-4.

37. Purifoy DJ, Beauchamp LM, de Miranda P, Ertl P, Lacey S, Roberts G, et al. Review of research leading to new anti-herpesvirus agents in clinical development: valaciclovir hydrochloride $(256 \mathrm{U}$, the L-valyl ester of acyclovir) and $882 \mathrm{C}$, a specific agent for varicella zoster virus. J Med Virol. 1993;Suppl 1:139-45.

38. Kim I, Chu XY, Kim S, Provoda CJ, Lee KD, Amidon GL. Identification of a human valacyclovirase: biphenyl hydrolase-like protein as valacyclovir hydrolase. J Biol Chem. 2003;278(28):25348-56. doi: 10.1074/jbc.M302055200M302055200 [pii].

39. Kim I, Song X, Vig BS, Mittal S, Shin HC, Lorenzi $\mathrm{PJ}$, et al. A novel nucleoside prodrug-activating enzyme: substrate specificity of biphenyl hydrolaselike protein. Mol Pharm. 2004;1(2):117-27.

40. Lai L, Xu Z, Zhou J, Lee KD, Amidon GL. Molecular basis of prodrug activation by human valacyclovirase, an alpha-amino acid ester hydrolase.
J Biol Chem. 2008;283(14):9318-27. doi: M709530200 [pii] 10.1074/jbc.M709530200.

41. Ganapathy ME, Huang W, Wang H, Ganapathy V, Leibach FH. Valacyclovir: a substrate for the intestinal and renal peptide transporters PEPT1 and PEPT2. Biochem Biophys Res Commun. 1998;246(2):470-5.

42. Han H, de Vrueh RL, Rhie JK, Covitz KM, Smith PL, Lee CP, et al. 5'-Amino acid esters of antiviral nucleosides, acyclovir, and AZT are absorbed by the intestinal PEPT1 peptide transporter. Pharm Res. 1998;15(8):1154-9.

43. Anand BS, Katragadda S, Mitra AK. Pharmacokinetics of novel dipeptide ester prodrugs of acyclovir after oral administration: intestinal absorption and liver metabolism. J Pharmacol Exp Ther. 2004;311(2):659-67. doi: 10.1124/jpet.104.069997 jpet.104.069997 [pii].

44. Eriksson AH, Elm PL, Begtrup M, Nielsen R, Steffansen B, Brodin B. hPEPT1 affinity and translocation of selected Gln-Sar and Glu-Sar dipeptide derivatives. Mol Pharm. 2005;2(3):242-9. doi: $10.1021 / \mathrm{mp} 050015+$.

45. Friedrichsen GM, Chen W, Begtrup M, Lee CP, Smith PL, Borchardt RT. Synthesis of analogs of Lvalacyclovir and determination of their substrate activity for the oligopeptide transporter in Caco-2 cells. Eur J Pharm Sci. 2002;16(1-2):1-13. doi: S0928098702000477 [pii].

46. Li J, Tamura K, Lee CP, Smith PL, Borchardt RT, Hidalgo IJ. Structure-affinity relationships of ValVal and Val-Val-Val stereoisomers with the apical oligopeptide transporter in human intestinal Caco-2 cells. J Drug Target. 1998;5(5):317-27. doi: 10.3109/10611869808997860.

47. Tamura K, Bhatnagar PK, Takata JS, Lee CP, Smith PL, Borchardt RT. Metabolism, uptake, and transepithelial transport of the diastereomers of ValVal in the human intestinal cell line, Caco-2. Pharm Res. 1996;13(8):1213-8.

48. Landowski CP, Lorenzi PL, Song X, Amidon GL. Nucleoside ester prodrug substrate specificity of liver carboxylesterase. J Pharmacol Exp Ther. 2006;316(2):572-80.

49. Lorenzi PL, Landowski CP, Song X, Borysko KZ, Breitenbach JM, Kim JS, et al. Amino acid ester prodrugs of 2-bromo-5,6-dichloro-1-(beta-Dribofuranosyl)benzimidazole enhance metabolic stability in vitro and in vivo. J Pharmacol Exp Ther. 2005;314(2):883-90.

50. Friedrichsen GM, Jakobsen P, Taub M, Begtrup M. Application of enzymatically stable dipeptides for enhancement of intestinal permeability. Synthesis and in vitro evaluation of dipeptide-coupled compounds. Bioorg Med Chem. 2001;9(10):2625-32.

51. Friedrichsen GM, Nielsen CU, Steffansen B, Begtrup M. Model prodrugs designed for the 
intestinal peptide transporter. A synthetic approach for coupling of hydroxy-containing compounds to dipeptides. Eur J Pharm Sci. 2001;14(1):13-9.

52. Dubowchik GM, Walker MA. Receptor-mediated and enzyme-dependent targeting of cytotoxic anticancer drugs. Pharmacol Ther. 1999;83(2):67123.

53. Gullbo J, Wickstrom M, Tullberg M, Ehrsson H, Lewensohn R, Nygren $\mathrm{P}$, et al. Activity of hydrolytic enzymes in tumour cells is a determinant for anti-tumour efficacy of the melphalan containing prodrug J1. J Drug Target. 2003;11(6):355-63.

54. Xing R, Wu F, Mason RW. Control of breast tumor cell growth using a targeted cysteine protease inhibitor. Cancer Res. 1998;58(5):904-9.

55. Bjornsson TD, Callaghan JT, Einolf HJ, Fischer V, Gan L, Grimm S, et al. The conduct of in vitro and in vivo drug-drug interaction studies: a
Pharmaceutical Research and Manufacturers of America (PhRMA) perspective. Drug Metab Dispos. 2003;31(7):815-32. doi: 10.1124/dmd.31.7.815 31/7/815 [pii].

56. Jia L, Liu X. The conduct of drug metabolism studies considered good practice (II): in vitro experiments. Curr Drug Metab. 2007;8(8):822-9.

57. Masri FA, Comhair SA, Koeck T, Xu W, Janocha A, Ghosh S, et al. Abnormalities in nitric oxide and its derivatives in lung cancer. Am J Respir Crit Care Med. 2005;172(5):597-605. doi: 200411-1523OC [pii] 10.1164/rccm.200411-1523OC.

58. Spink DC, Spink BC, Cao JQ, DePasquale JA, Pentecost BT, Fasco MJ, et al. Differential expression of CYP1A1 and CYP1B1 in human breast epithelial cells and breast tumor cells. Carcinogenesis. 1998;19(2):291-8. 